\title{
Elevated endocan levels are associated with development of renal failure in ARDS patients
}

\author{
L Rahmania ${ }^{*}$, D Orbegozo Cortés ${ }^{2}$, M Irazabal ${ }^{2}$, M Mendoza $^{2}$, C Santacruz ${ }^{2}$ D De Backer ${ }^{2}$, J Creteur $^{2}$, J-L Vincent ${ }^{2}$ \\ From ESICM LIVES 2015 \\ Berlin, Germany. 3-7 October 2015
}

\section{Intr}

Endocan is a proteoglycan preferentially expressed in pulmonary and renal vasculatures and a marker of endothelial dysfunction [1]. Recently, elevated plasma endocan concentrations have been associated with chronic kidney disease stage after renal transplantation [2], but data on acute kidney injury are lacking.

\section{Objectives}

The aim of the study was to determine whether plasma endocan levels were correlated with renal function in patients with acute respiratory distress syndrome (ARDS) and could predict the need for renal replacement therapy (RRT), as an indicator of acute renal dysfunction, during the ICU stay.

\section{Methods}

This was a post hoc analysis of prospectively collected data from 96 consecutive patients with ARDS (Berlin definition) who were not receiving RRT at diagnosis. Plasma endocan concentrations were measured using a quantitative ELISA method (Lunginov, France). We analyzed the predictive value of creatinine and endocan levels at diagnosis on the subsequent need for RRT using the area under the receiver operating characteristic curve (ROC AUC). We dichotomized values of creatinine (using a renal SOFA cut-off of $1.2 \mathrm{mg} / \mathrm{dL}$ ) and endocan (best sensitivity and specificity based on the ROC curve) to predict need for RRT. All analyses were performed using SPSS 22.0 and a $\mathrm{p}$ value $<0.05$ was considered as significant. $\mathrm{Al}$ values are presented as median with p25-75.

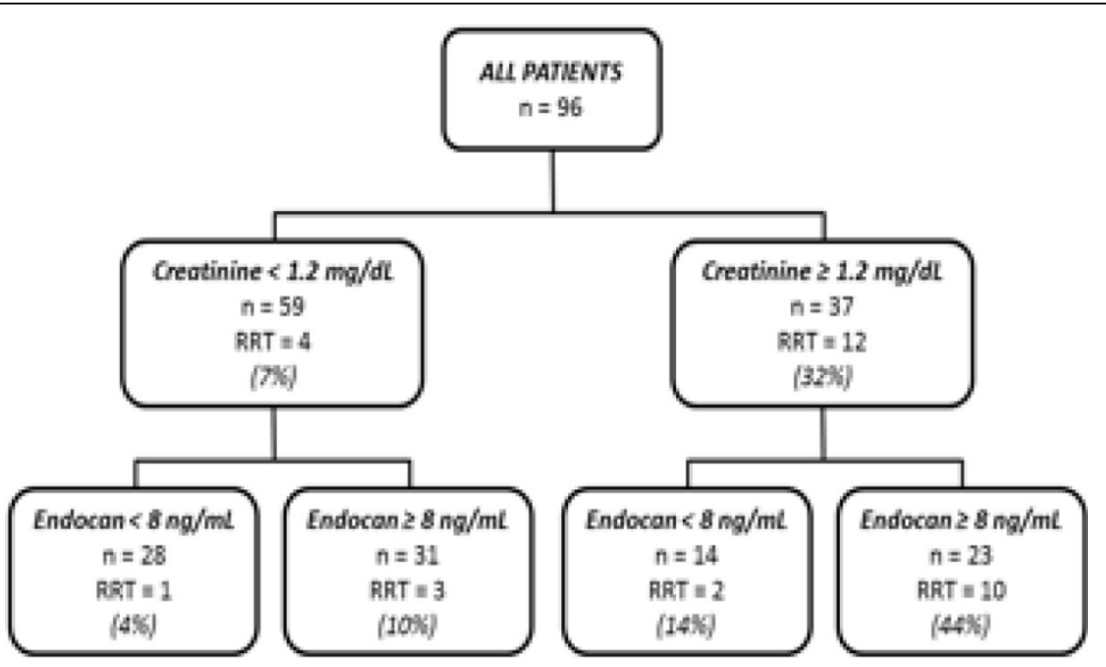

Figure 1 Need for RRT according to creatinine and endocan. 


\section{Results}

Of the 96 patients [APACHE II score 21 (17-27), SOFA score 9 (6-12), creatinine $1.0(0.7-1.4) \mathrm{mg} / \mathrm{dL}], 66 \%$ had sepsis, $53 \%$ needed norepinephrine and $17 \%$ needed RRT at some point after diagnosis. Patients who needed RRT had higher APACHE II scores [28(21:30) vs 21 (16:26), $\mathrm{p}=0.03$ ], higher SOFA scores [12(10:16) vs $8(5: 11), \mathrm{p}<0.01]$, higher blood creatinine levels [1.8(1.2:2.7) vs 0.9(0.7:1.3), $\mathrm{p}<0.01]$ and higher endocan levels [10.0(8.1:30.6) vs $8.1(6.0: 10.8), \mathrm{p}=0.02]$ than those who did not need RRT. ROC AUCs (IC 95\%) for creatinine alone, endocan alone or the two together to predict RRT were 0.72 (0.58-0.85), 0.69 (0.53-0.85) and 0.77 (0.64-0.89), respectively. The best ROC AUC cutoff for endocan was $8 \mathrm{ng} / \mathrm{mL}$. Endocan and creatinine values were poorly correlated $\left(r^{2}=0.052, p=0.03\right)$; when combined they predicted the need for RRT better than did creatinine alone (Figure 1).

\section{Conclusions}

At ARDS diagnosis, elevated endocan levels are associated with subsequent development of renal failure.

\section{Authors' details}

'Erasme University Hospital, Université Libre de Bruxelles, Department of Intensive Care, Brussels, Belgium. ${ }^{2}$ Department of Intensive Care, Erasme University Hospital, Université Libre de Bruxelles, Brussels, Belgium.

Published: 1 October 2015

\section{References}

1. Lassalle, et al: ESM-1 is a novel human endothelial cell-specific molecule expressed in lung and regulated by cytokines. J Biol Chem 1996, 271:20458-64.

2. SU, et al: Serum Endocan correlated with stage of chronic kidney disease and deterioration in renal transplant recipients. Transplant Proc 2014, 46(2):323-7.

doi:10.1186/2197-425X-3-S1-A264

Cite this article as: Rahmania et al:: Elevated endocan levels are associated with development of renal failure in ARDS patients. Intensive Care Medicine Experimental 2015 3(Suppl 1):A264.

\section{Submit your manuscript to a SpringerOpen ${ }^{\mathcal{O}}$ journal and benefit from:}

- Convenient online submission

- Rigorous peer review

- Immediate publication on acceptance

- Open access: articles freely available online

- High visibility within the field

- Retaining the copyright to your article

Submit your next manuscript at $\gg$ springeropen.com 